\title{
COMMENTARY
}

\section{How to approach genome wars in sepsis?}

\author{
Jack Hawiger ${ }^{1 *}$ and James M Musser ${ }^{2}$
}

\begin{abstract}
Sepsis continues to pose a clear challenge as one of the most difficult and costly problems to treat and prevent. Sepsis is caused by systemic or localized infections that damage the integrity of microcirculation in multiple organs. The challenge of sepsis and its longterm sequelae was addressed by the National Institutes of Health National Heart Lung and Blood Institute Division of Blood Diseases and Resources. Defining sepsis as severe endothelial dysfunction syndrome that causes multiorgan failure in response to intravascular or extravascular microbial agents, the National Heart Lung and Blood Institute panel proposed the concept of genome wars as a platform for new diagnostic, therapeutic, and preventive approaches to sepsis.
\end{abstract}

Sepsis is one of the most difficult and costly problems to treat and prevent. It is caused by systemic or localized infections that damage the integrity of microcirculation in multiple organs. In sepsis, severe endothelial dysfunction underlies ischemic injury to the lungs, kidney, heart, brain, and other organs, leading to over 200,000 deaths annually among the estimated 700,000 to 900,000 patients in US hospitals. Mortality due to sepsis varies, peaking early in the first year of life (for example, neonatal sepsis), remaining at $10 \%$ in children, and then steadily climbing to $38.4 \%$ at age 85 [1]. The US hospitalization rates for sepsis among persons aged 65 to 74 and 75 to 84 years increased $57 \%$ and $52 \%$, respectively, between 2000 and 2007 [2]. In 2008, the most expensive hospital stays in the United States exceeding $\$ 500,000$ per hospitalization were due to sepsis (average 22 days) [3]. These most recent statistics indicate that current US annual expenditures for patients with sepsis are probably much higher than previous estimates of $\$ 17$ billion [1], probably exceeding two-thirds of the entire 2011 budget

*Correspondence: jack.hawiger@vanderbilt.edu

"Vanderbilt University School of Medicine, Department of Medicine, Division of

Allergy Pulmonary and Critical Care Medicine, 1161 21st Avenue South, T-1218

MCN, Nashville, TN 37232-2650, USA

Full list of author information is available at the end of the article of $\$ 30.7$ billion for biomedical research funded by the National Institutes of Health. Even worse, sepsis survivors suffer incapacitating cognitive impairment and functional disability, posing tremendous emotional and financial challenges [4]. Sepsis undermines advances in medical and surgical management of multiple diseases [1]. While the worldwide Surviving Sepsis Campaign has developed excellent standards of care [5], the only US Food and Drug Administration-approved drug for adult severe sepsis - recombinant human activated protein $\mathrm{C}$ - was introduced a decade ago [6].

A report entitled 'Blood Systems Response to Sepsis' published online by the National Heart Lung and Blood Institute (NHLBI) Division of Blood Diseases and Resources addresses the challenge of sepsis and its long-term sequelae [7]. An interdisciplinary panel of experts analyzed the problem of sepsis in the context of a genomic approach to patients and their microbial invaders. An interrelationship between the host's genetic constitution and the invading pathogen's genetic prowess led to the concept of genome wars, which determine the outcome of sepsis (Figure 1). Decoding the molecular events at work in these genome wars is now economically feasible due, in part, to spectacular advances in genomic technologies - such as deep transcriptome, exome, and whole genome sequencing - that are currently available to individual investigators at a reasonable cost.

The close encounters of invading pathogens and the host's innate and adaptive immunity contribute to loss of homeostatic function of the microvascular endothelium in multiple organs. This loss is exemplified by two major complications of sepsis: acute respiratory distress syndrome and disseminated intravascular coagulation. Why, how, and when these complications emerge in some but not other patients, contributing to irreversible multiorgan failure and death, are questions awaiting further study. In this context, the prevailing sepsis paradigm as systemic inflammatory response to infection - commonly referred to as a cytokine storm - seems inadequate. The same elevated cytokines are recorded in a multitude of autoimmune diseases without the vascular collapse [8], while trials of anticytokine therapeutics were unsuccessful in treating sepsis [9]. The NHLBI report proposes the unifying concept of sepsis as a severe endothelial dysfunction syndrome that causes multiorgan 


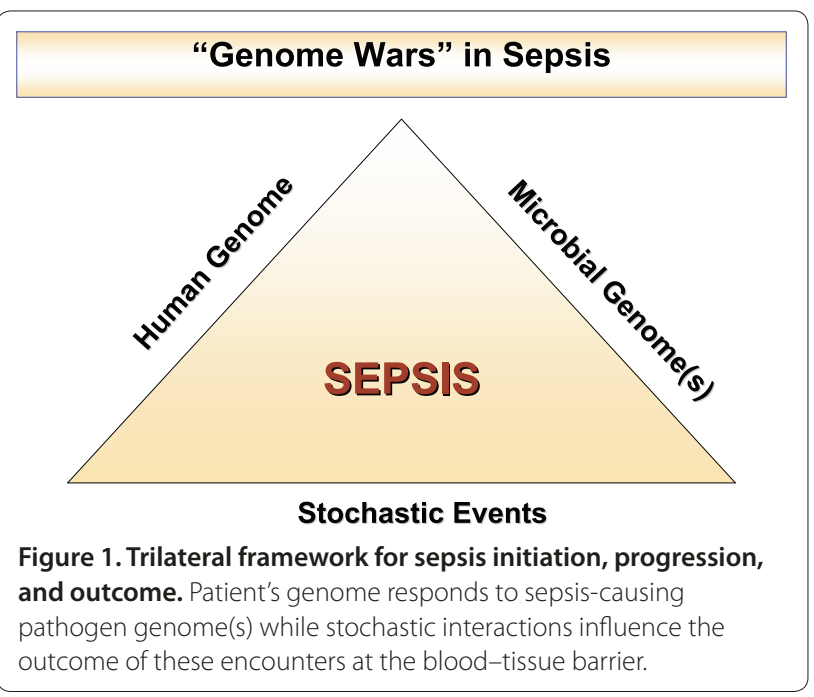

failure in response to intravascular or extravascular microbial agents [7]. Consistent with this concept, endothelial dysfunction leads to a widespread increase in vascular permeability [10].

The first proposed approach is to harness state-of-theart genomic technologies for establishing landmarks of sepsis susceptibility, progression, and outcome. A growing number of genetic variations are being discovered in almost every known vanguard of innate and adaptive immunity. These defenses are challenged by the extensive inter-species and intra-species genetic variability of diverse microbial pathogens that cause sepsis (Figure 1). Highly advanced genomic technologies and bioinformatics are likely to decode those polymorphic features to be utilized as new biomarkers for sepsis progression, prognosis, and personalized therapy.

The second proposed approach calls for a better understanding of the main theater of sepsis: the bloodtissue barrier, which is formed by the microvascular endothelium and adjoining structures. Cell and structural biology as well as molecular imaging applied to analysis of human and animal blood and vascular cells should be extended to organ-specific vascular beds [11]. Such analysis would correlate with changes in the coagulation and fibrinolysis systems, and the function of platelets, neutrophils, and other blood cells that stick to activated and damaged endothelium. New animal models are needed that more closely resemble human blood and vascular systems to facilitate translation of basic discoveries into bedside applications.

The third approach to solving the problem of sepsis focuses on the evolving interplay between pathogen and host to discover pathogen-specific or nonspecific turning points at which intervention can alter the course of sepsis before damage to vital organs becomes irreversible. These poorly understood stochastic interactions (Figure 1) may explain why speed is life, because a 6-hour delay in starting antimicrobial therapy in patients with hypotension and infection correlated with dramatically higher mortality (7.6\% decrease in survival per hour of delay) [12]. Moreover, a delay in implementation of the guidelines developed by the Surviving Sepsis Campaign resulted in higher mortality and longer ICU stay [13]. The NHLBI report offers translational strategies to bridge basic science and clinical investigation to develop new therapies for sepsis.

Several years ago, the NHLBI-sponsored request for applications that funded 'Plasma Proteins with Potential Therapeutic Usefulness' spawned the seminal studies for the only US Food and Drug Administration-approved drug for sepsis in adults - activated protein C [6]. A decade - and millions of sepsis victims - later, it is now essential to approach the sepsis genome wars with vigorous efforts to translate emerging genomic information into new countermeasures. Sepsis is a towering public health problem worldwide, growing in magnitude as the population ages.

\section{Abbreviations}

NHLBI, National Heart Lung and Blood Institute.

\section{Competing interests}

$\mathrm{JH}$ is the co-inventor on patents held by employer Vanderbilt University, and has not received any extra reimbursements and fees related to this article.

\section{Authors' contributions}

Both authors contributed to the conceptual development of this commentary, which was written by $\mathrm{JH}$ and edited by JMM.

\section{Acknowledgments}

The authors appreciate the invaluable contributions to the NHLBI Workshop on 'Blood Systems Response to Sepsis' by the co-chair, David Ginsburg, MD (University of Michigan, Ann Arbor, MI, USA) and the Working Group members: Jean-Laurent Casanova, MD, PhD (The Rockefeller University, New York, NY, USA); Jay Degen, PhD (University of Cincinnati, Cincinnati, OH, USA); Bruce Furie, MD (Harvard Medical School, Boston, MA, USA); John H Griffin, PhD (The Scripps Research Institute, La Jolla, CA, USA); Olaf Schneewind, MD, PhD (University of Chicago, Chicago, IL, USA); Denisa D Wagner, PhD (Harvard Medical School, Boston, MA, USA); Aimee Zaas, MD, MHS (Duke University, Durham, NC, USA); and Rita Sarkar, PhD (NHLBI Division of Blood Diseases and Resources, National Institutes of Health, Bethesda, MD, USA) as a Program Contact and Working Group Coordinator. The authors also wish to thank the Working Group consultants: Kenneth A Bauer, MD (Harvard Medical School, Boston, MA, USA); Shaun Coughlin, MD, PhD (University of California, San Francisco, CA, USA); William P Fay, MD (University of Missouri, Columbia, MO, USA); Steven Holland, MD (NIAID, National Institutes of Health, Bethesda, MD, USA); J Evan Sadler, MD, PhD (Washington University, St Louis, MO, USA); and Ajit Varki, MD (University of California, San Diego, CA, USA). The pivotal support of Susan B Shurin, MD, Acting Director, National Heart Lung and Blood Institute, is gratefully acknowledged. The authors regret that due to strict limits on the number of references they could not cite all relevant sources.

\section{Author details}

'Vanderbilt University School of Medicine, Department of Medicine, Division of Allergy Pulmonary and Critical Care Medicine, 1161 21st Avenue South, T-1218 MCN, Nashville, TN 37232-2650, USA. ²Department of Pathology and Genomic Medicine, The Methodist Hospital System and Research Institute, 6565 Fannin Street, B490, Houston, Texas 77030, USA.

Published: 2 December 2011 


\section{References}

1. Angus DC, Linde-Zwirble WT, Lidicker J, Clermont G, Carcillo J, Pinsky MR: Epidemiology of severe sepsis in the United States: analysis of incidence, outcome, and associated costs of care. Crit Care Med 2001, 29:1303-1310.

2. Hospitalization Rates for Patients Aged $>65$ Years with Septicemia or Sepsis by Age Group - National Hospital Discharge Survey, United States, 2000-2007 [http://www.cdc.gov/mmwr/preview/mmwrhtml/mm5934a6. $\mathrm{htm}]$

3. Mitka M: Hospitalizations for extreme conditions mean extreme expenses, study verifies. JAMA 2010, 304:2579-2580.

4. Iwashyna TJ, Ely EW, Smith DM, Langa, KM: Long term cognitive impairment and functional disability among survivors of severe sepsis. JAMA 2010, 304:1787-1794.

5. Dellinger RP, Levy MM, Carlet JM, Bion J, Parker MM, Jaeschke R, Reinhart K, Angus DC, Brun-Buisson C, Beale R, Calandra T, Dhainaut JF, Gerlach H, Harvey M, Marini JJ, Marshall J, Ranieri M, Ramsay G, Sevransky J, Thompson BT, Townsend S, Vender JS, Zimmerman JL, Vincent JL; International Surviving Sepsis Campaign Guidelines Committee; American Association of CriticalCare Nurses; American College of Chest Physicians; American College of Emergency Physicians; Canadian Critical Care Society; European Society of Clinical Microbiology and Infectious Diseases, et al:. Surviving Sepsis Campaign: international guidelines for management of severe sepsis and septic shock. Crit Care Med 2008, 36:296-327.

6. Bernard GR, Vincent JL, Laterre PF, LaRosa SP, Dhainaut JF, LopezRodriguez A, Steingrub JS, Garber GE, Helterbrand JD, Ely EW, Fisher CJ Jr; Recombinant human protein CWorldwide Evaluation in Severe Sepsis (PROWESS) study group: Efficacy and safety of recombinant human activated protein c for severe sepsis. N Engl J Med 2001, 344:699-709.
7. National Heart Lung and Blood Institute: Blood Systems Response to Sepsis [http://www.nhlbi.nih.gov/meetings/workshops/bsrts.htm]

8. Murakami M, Nishimoto N: The value of blocking IL-6 outside of rheumatoid arthritis: current perspective. Curr Opin Rheumatol 2011, 23:273-277.

9. Opal SM, Cross AS: Clinical trials for severe sepsis. Past failures and future hopes. Infect Dis Clin North Am 1999, 13:287-297.

10. Goldenberg NM, Steinberg BE, SlutskyAS, Lee WL: Broken barriers: a new take on sepsis pathogenesis. Sci Trans/ Med 2011, 3:88ps25.

11. Rosenberg RD, Aird WC: Vascular-bed-specific hemostasis and hypercoagulable states. N Engl J Med 1999, 340:1555-1564.

12. Kumar A, Roberts D, Wood KE, Light B, Parrillo JE, Sharma S, Suppes R, Feinstein D, Zanotti S, Taiberg L, Gurka D, Kumar A, Cheang M: Duration of hypotension before initiation of effective antimicrobial therapy is the critical determinant of survival in human septic shock. Crit Care Med 2006, 34:1589-1596.

13. Zambon M, Ceola M, Almeida-de-Castro R, Gullo A, Vincent UL: Implementation of the Surviving Sepsis Campaign guidelines for severe sepsis and septic shock: we could go faster. J Crit Care 2008, 23:455-460.

doi:10.1186/cc10482

Cite this article as: Hawiger J, Musser JM: How to approach genome wars in sepsis? Critical Care 2011, 15:1007. 